\title{
A METHOD FOR BUILT-UP AREA EXTRACTION USING DUAL POLARIMETRIC ALOS PALSAR
}

\author{
S. Sinha ${ }^{1, *}$, A. Santra ${ }^{1}$, S. S. Mitra ${ }^{1}$ \\ ${ }^{1}$ Department of Civil Engineering, Haldia Institute of Technology, Haldia , India - sumanrumpa.sinha@gmail.com
}

Commission V, SS: Infrastructure and Development Planning

KEY WORDS: Built-up Area, Synthetic Aperture Radar, ALOS PALSAR, Backscatter, Classification

\begin{abstract}
:
Mapping of the built-up area is a task of exigency as the area supports varieties of anthropogenic activities and is important for several ecosystem services. The task becomes more complicated owing to similarities in spectral characteristics with the bare soil. A new radar-based approach is proposed using Synthetic Aperture Radar (SAR) HH/HV dual polarized L-band ALOS PALSAR data. Sigma nought $\left(\sigma^{\circ}\right)$ values are extracted from the HH and HV polarized data. HH and HV sigma nought images are ratioed and normalized and then equated together in a unique combination to generate an index that is developed, cross-checked and validated over multiple regions, with simultaneous inputs from Ground truth (GT) data. Maps developed using the index is classified into built-up and non built-up areas, where the results show that the proposed method is very effective for built-up area detection. The approach adopted in this study is acceptable due to its high accuracy, simplicity and reliability; and hence easy to replicate.
\end{abstract}

\section{INTRODUCTION}

Rapid globalization leads to urbanization. Several problems originated due to rapid urbanization, most of which are irreversible. The increasing rate of urbanization and in-turn the built-up areas results in an interconnected consequence of environmental issues, with decrease of vegetated areas and the expansion of urban heat island effects, affecting the overall ecosystem and biodiversity. This has resulted in investigation concerning identification and extraction of built-up areas for urban planning, climate studies and resource management using satellite data (Bramhe et al., 2018).

Remote sensing is used to establish considerable assistance in the analysis of urban ecosystems through objective and verifiable characterization of urban composition. Mapping of land features began with the conventional multi-spectral analysis; however, with satisfactory level of classification accuracy owing to spectral mixture of heterogeneous land features Several studies have used optical spectral characteristics in remote sensing to detect built-up areas (Sinha et al., 2015a, 2018); but the heterogeneity in the satellite images results in complex patterns in the images that are complex to understand, which make the retrieval of accurate information from images even more intricate and challenging. Built-up features share similar spectral characteristics with the bare soil, river sands and fallow lands. Hence, spectral properties are not adequate to discriminate built-up areas. In order to overcome such intricacy, radar or SAR (Synthetic Aperture Radar) remote sensing are considered as the best alternative, as the targetsignal interaction rely on the scattering properties of the ground features, depending on which backscatter values are generated (Sinha et al., 2015b).

SAR has been applied to extract built-up information over various scales in somewhat limited studies, either singly or with optical data. SAR data from Radarsat has been used for urban land-cover mapping with high classification accuracy ( $\mathrm{Hu}$ and Ban, 2008). Contextual information from SAR data like Radarsat-2 and TerraSAR-X were used for urban land use mapping with moderate classification accuracy (Chen et al., 2013; Lv et al., 2015). Texture measures have been found to be beneficial for extracting information related to built-up features (Corbane et al., 2008; Aghababaee et al., 2013; Shao et al., 2016). Polarimetric capabilities of SAR data from Sentinel-1 were investigated for land cover mapping in urban areas, where the use of dual polarization proved superior to single polarization (Abdikan et al., 2016). Classification algorithms like Maximum likelihood and K-means are effective for classifying segmented images generated from SAR data (Wang et al., 2016). Data fusion technique is also explored for delineation of urban impervious surface from the fused data product (Shao et al., 2016). Integrated use of optical and SAR has also been explored for extraction of urban and built-up areas (Corbane et al., 2008; Qin et al., 2017). Synergic use of both optical and SAR surmounts the mutual constraints and results in improved analysis in most cases (Sinha et al., 2016).

In this paper, we introduce a SAR backscatter based index that can automatically extract built-up areas from SAR imagery. The co-polarization backscatter show a unique pattern over built-up areas than the cross-polarizations (Liu, 2016), hence, ratio and/or normalization between the co- and cross-polarizations has the capability to distinguish built-up areas from other land use land cover (LULC) features. Backscatter or sigma nought values from $\mathrm{HH}$ and $\mathrm{HV}$ polarizations are combined in a unique fashion to generate the index and is applied over multiple site to establish its potentiality and validity. The approach can easily be implemented over various regions as it can work independently without using training samples or self-defined thresholds.

\footnotetext{
* Corresponding author
} 


\section{STUDY AREA AND DATA USED}

The study had been carried out over multiple sites in the Indian subcontinent as depicted in Figure 1.

Site 1: South Kolkata, West Bengal. Megacity, high population density. Coordinates: $22.57^{\circ} \mathrm{N}$ and $88.36^{\circ} \mathrm{E}$.

Site 2: Haldia, West Bengal. Industrial, moderately low population density. Coordinates: $22.03^{\circ} \mathrm{N}$ and $88.06^{\circ} \mathrm{E}$.

Site 3: Munger, Bihar. Moderately low population density. Coordinates: $25.37^{\circ} \mathrm{N}$ and $86.47^{\circ} \mathrm{E}$.

Site 4: Jamalpur, Bihar. Very low population density. Coordinates: $25.31^{\circ} \mathrm{N}$ and $86.49^{\circ} \mathrm{E}$.

Munger-Jamalpur is known as the twin city.

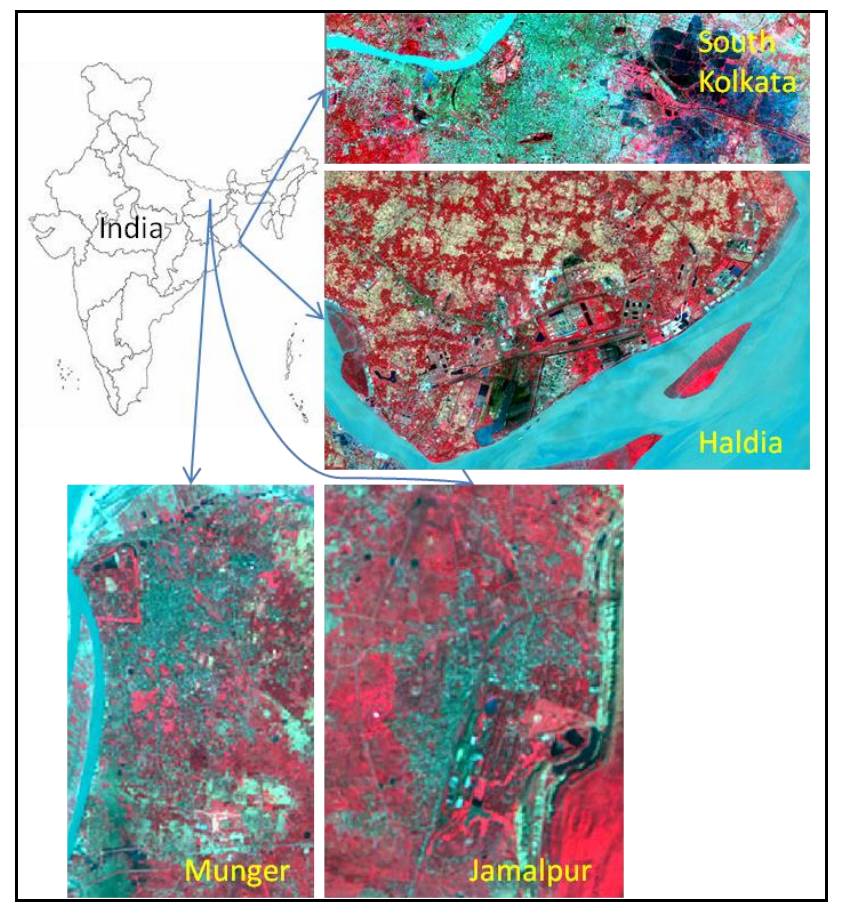

Figure 1. Location of the study sites (1. South Kolkata, 2. Haldia, 3. Munger, 4. Jamalpur) under investigation (Standard False Colour Composite LISS-III images with Green, Red and NIR bands in Blue, Green and Red channels respectively).

SAR data from Fine Beam Dual polarized HH/HV L-band ALOS PALSAR imageries are used in this study for all the sites. Specifications of the data are mentioned in Table 1.

\begin{tabular}{cc}
\hline Remote sensing data type & SAR \\
\hline Satellite & ALOS \\
Sensor & PALSAR \\
Launching country & Japan (JAXA) \\
(Organization) & $24^{\text {th }}$ January, 2006 \\
Date of launch & $25 \mathrm{~m}$ \\
Spatial resolution & $70 \mathrm{~km}\left(34.3^{\circ}\right.$ incident angle $)$ \\
Swath width & L-band, $15-30 \mathrm{~cm}$; Fine Beam \\
Wavelengths; polarization & Dual (HH/HV) \\
Year of data acquisition & 2010 \\
Source of data acquisition & JAXA, Japan \\
\hline
\end{tabular}

Table 1. Satellite data specifications

\section{METHODOLOGY}

\subsection{SAR data processing}

Raw SAR data procured as single-look complex (SLC) data are multi-looked to convert the complex data to real numbered intensity data. Azimuth to range ratio of $3: 1$ is applied to generate images with squared pixels. The intensity images are converted to power or decibel images by radiometric calibration using Equation 1 (Sinha et al., 2016). Speckle reduction is performed using Gamma map filters. Multi-looking also help in speckle reduction. Geocoding is done using orbital parameters with SRTM DEM resampled to $25 \mathrm{~m}$ pixel size by nearest neighbourhood algorithm and re-projected to UTM-WGS84 coordinate system using the Range-Doppler Approach for terrain correction.

$\sigma^{\circ}=10 * a \log 10(D N)+A_{o}$

where, $\sigma^{0}$ is the backscatter coefficient or sigma nought values in decibels $(\mathrm{dB}), \mathrm{DN}$ is the power (or intensity) image, $\mathrm{A}_{0}=-$ $115 \mathrm{~dB}$ is the calibration factor for ALOS PALSAR.

\subsection{SAR-based index}

$\mathrm{HH}$ backscatter $\left(\mathrm{HH}_{\sigma}{ }^{0}\right)$ and $\mathrm{HV}$ backscatter $\left(\mathrm{HV}_{\sigma}{ }^{0}\right)$ values are equated to obtain ratioed (a) and normalized (b) images. Variability is observed between $\mathrm{e}^{\mathrm{a}}$ and $\mathrm{e}^{\mathrm{b}}$ for built-up features and so, the exponential products are further normalized. It resulted in a unique pattern that became even more prominent when combined together in an exponential equation, expressed as Equation 2 that helped distinguish the built-up feature class entirely from the other remaining feature classes, like water, vegetation and bare soil, specifically after when the exponential normalized product ' $\left(\mathrm{e}^{\mathrm{a}}-\mathrm{e}^{\mathrm{b}}\right) /\left(\mathrm{e}^{\mathrm{a}}+\mathrm{e}^{\mathrm{b}}\right)$ ' was subtracted from the normalized product ' $a$ ' to reduce the urban class overlapping with the water class.

Built-up Index $=\mathrm{a}-\mathrm{c}$

where, $\mathrm{a}=\left[\left(\mathrm{HH}_{\sigma}{ }^{0}-\mathrm{HV}_{\sigma}{ }^{0}\right) /\left(\mathrm{HH}_{\sigma}{ }^{0}+\mathrm{HV}_{\sigma}{ }^{0}\right)\right], \mathrm{b}=\left(\mathrm{HH}_{\sigma}{ }^{0} / \mathrm{HV}_{\sigma}{ }^{0}\right), \mathrm{c}$ $=\left(\mathrm{e}^{\mathrm{a}}-\mathrm{e}^{\mathrm{b}}\right) /\left(\mathrm{e}^{\mathrm{a}}+\mathrm{e}^{\mathrm{b}}\right), \mathrm{e}=$ exponential function.

\section{RESULTS AND ANALYSIS}

\subsection{Responses of $\mathrm{HH} / \mathrm{HV}$ polarizations}

The correlation graph between the $\mathrm{HH}_{\sigma}{ }^{0}$ and $\mathrm{HV}_{\sigma}{ }^{0}$ in Figure 2 shows that the higher values correspond to built-up class; while generally much higher for $\mathrm{HH}$ in comparison to HV. The least values correspond to the water class, while vegetation and bare soil lie in between.
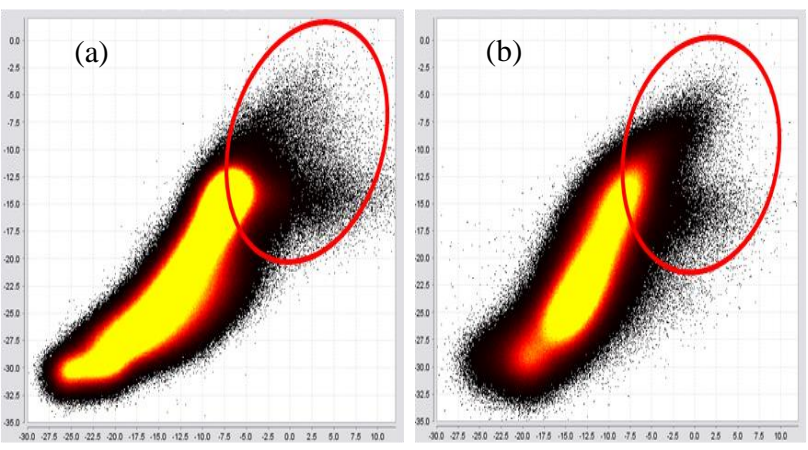

Figure 2. Relation between $\mathrm{HH}_{\sigma}{ }^{0}$ (x-axis) and $\mathrm{HV}_{\sigma}{ }^{0}$ (y-axis) showing built-up class encircled in 'red' over (a) KolkataHaldia site and (b) Munger-Jamalpur twin city site. 


\subsection{Classification using SAR-based index}

The proposed SAR derived index of Equation 2 is applied on the study site PALSAR imageries and the output maps, after binary classification into built-up and non built-up areas are illustrated in Figure 3. Built-up areas are demarcated in 'black' and non built-up areas in 'white'.
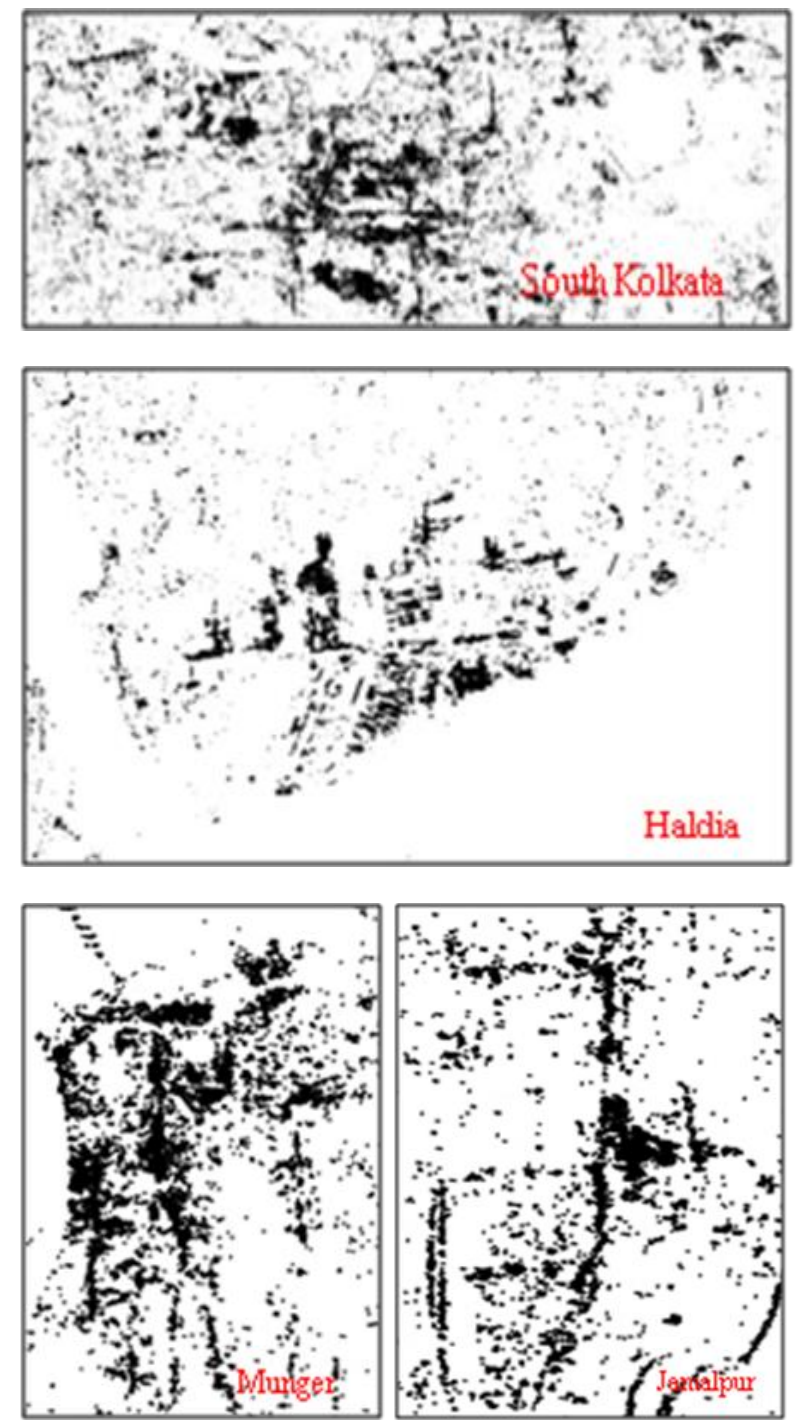

Figure 3. Classified binary images from the SAR-based indexed maps distinguishing built-up (in black) from non builtup (white) areas.

\subsection{Responses of the index}

The responses of the index for the sites over different land use land cover types are recorded and a graph is designed, as depicted in Figure 4. The red line in the graph shows the builtup class that can be clearly distinguished from the other classes, viz. water, vegetation and bare soil. Built-ups are visualized as a complete separate class with mostly negative values of the index; while all the remaining classes show a positive index value. Mean and Standard Deviation (SD) of the index values shows negative mean values only for built-up areas, while positive for the rest classes (Table 2). This has also been represented in Figure 5, where maximum, minimum and mean index values for the major LULC classes over all the study sites are shown. It is evident from the figure that the values for builtup areas are non-overlapping with that of other classes, and is purely negative unlike other classes.

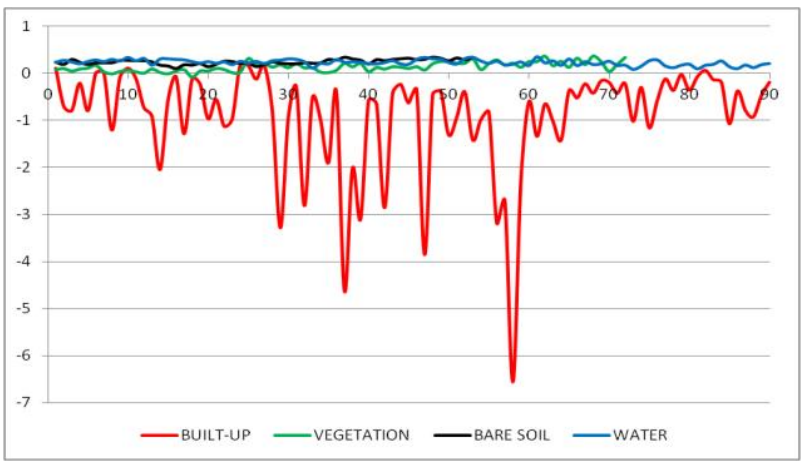

Figure 4. Index values (y-axis) for feature classes.

\begin{tabular}{|l|l|l|l|l|}
\hline & Built-up & Vegetation & Bare soil & Water \\
\hline Mean & -0.90003 & 0.142524 & 0.245075 & 0.237397 \\
\hline SD & 1.118926 & 0.100006 & 0.05316 & 0.059535 \\
\hline
\end{tabular}

Table 2. Mean and SD values of index for major LULC classes

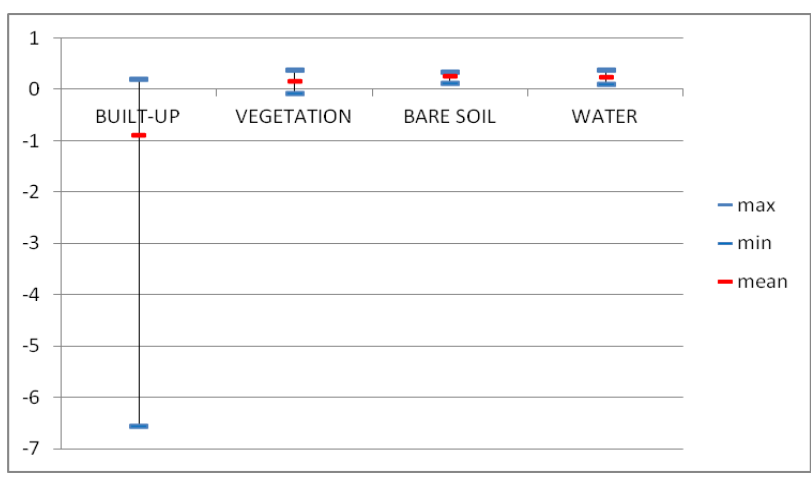

Figure 5. Index values (y-axis) for feature classes.

\subsection{Classification accuracy}

Figure 3 demonstrates the classified binary image illustrating the extracted built-up area marked in 'black' and the non builtup area in 'white'. Accuracy assessment for the classification is performed. A total of 900 sample points are randomly selected over the sites as reference points. Maximum likelihood algorithm is used for supervised classification (Sinha et al., 2013) and the accuracy is recorded in terms of overall accuracy (OA) and kappa coefficient (k) for classification of built-up and non built-up areas (Table 3). Overall accuracy of classification is $91.89 \%$ with $\mathrm{k}$ value of 0.83 .

\begin{tabular}{|l|r|r|l|l|l|}
\hline & Built-up & Non Built-up & & OA & $\mathrm{k}$ \\
\hline Built-up & 301 & 41 & 342 & 91.89 & 0.83 \\
\hline Non Built-up & 32 & 526 & 558 & & \\
\hline & 333 & 567 & 900 & & \\
\hline & & & 900 & & \\
\hline
\end{tabular}

Table 3. Accuracy assessment report 


\section{CONCLUSIONS}

Efficient delineation of built-up areas is of great ecological and environmental importance but is a challenge that researchers experience. Worldwide limited applicability of multi-spectral optical remote sensing for automatic extraction of built-up features led into the intervention of SAR technology in this research. The study illustrated an innovative approach in effectively delineating built-up areas with SAR derived index using dual polarimetric properties of $\mathrm{HH}$ and $\mathrm{HV}$ polarizations of ALOS PALSAR data. The method is developed, tested and validated over multiple sites. It resulted in about $92 \%$ overall accuracy in mapping built-up areas. The method adopted is acceptable, simple, reliable and replicable with high accuracy in mapping the built-up features.

The study is important for change detection of built-up areas, urban management and policy making, LULC mapping, urban sprawl assessment, urban microclimate studies, urban heat island, etc. and other related studies. Proper assessment of the spatial extent of built-up areas is essential for accurate understanding and calculating these interconnected built-up attributes. With the arrival of various SAR missions like ALOS and RISAT follow-ups, NISAR, MAPSAR, etc., which can provide circular and quad polarizations along with single and dual polarization for further improvements in this research.

\section{ACKNOWLEDGEMENTS}

We sincerely acknowledge Japan Aerospace Exploration Agency (JAXA, Japan) for providing the SAR data. We are also thankful to the Geoinformatics Cell of Department of Civil Engineering, Haldia Institute of Technology (India) where the research was performed. We express sincere gratitude to Science and Engineering Research Board (SERB), Department of Science and Technology (DST), Government of India for providing funds under SERB National Post-Doctoral fellowship (SERB NPDF) scheme (File Number: PDF/2015/000043).

\section{REFERENCES}

Abdikan, S., Sanli, F.B., Ustuner, M., Calò, F., 2016. Land cover mapping using Sentinel-1 SAR data. In: The International Archives of the Photogrammetry, Remote Sensing and Spatial Information Sciences, Vol. XLI-B7, pp. 757-761. doi:10.5194/isprs-archives-XLI-B7-757-2016.

Aghababaee, H., Niazmardi, S., Amini, J., 2013. Urban area extraction in SAR data. In: The International Archives of the Photogrammetry, Remote Sensing and Spatial Information Sciences, Vol. XL-1/W3, pp. 1-5. doi:10.5194/isprsarchivesXL-1-W3-1-2013.

Bramhe, V.S., Ghosh, S.K., Garg, P.K., 2018. Extraction of built-up areas using convolutional neural networks and transfer learning from Sentinel-2 satellite images. In: The International Archives of the Photogrammetry, Remote Sensing and Spatial Information Sciences, Vol. XLII-3, pp. 79-85. doi:10.5194/isprs-archives-XLII-3-79-2018.

Chen, Z., Zhang, Y., Guindon, B., Esch, T., Roth, A., Shang, J., 2013. Urban land use mapping using high resolution SAR data based on density analysis and contextual information. Canadian Journal of Remote Sensing, 38(6), pp. 738-749. doi: $10.5589 / \mathrm{m} 13-002$.
Corbane, C., Faure, J.-F., Baghdadi, N., Villeneuve, N., Petit, M., 2008. Rapid urban mapping using SAR/optical imagery synergy. $\quad$ Sensors, 8 (11), pp. 7125-7143. doi:10.3390/s8117125.

Hu, H., Ban, Y., 2008. Urban land-cover mapping and change detection with Radarsat SAR data using neural network and rule-based classifiers. In: XXI Congress of International Society for Photogrammetry and Remote Sensing (ISPRA). Beijing, China, pp. 1549-1553.

Liu, C., 2016. Analysis of Sentinel-1 SAR data for mapping standing water in the Twente region. M.Sc Thesis. University of Twente, Enschede, The Netherlands.

Lv, Q., Dou, Y., Niu, X., Xu, J., Xu, J., Xia, F., 2015. Urban land use and land cover classification using remotely sensed SAR data through deep belief networks. Journal of Sensors, 2015(10). doi:10.1155/2015/538063.

Qin, Y., Xiao, X., Dong, J., Chen, B., Liu, F., Zhang, G., Zhang, Y., Wang, J., Wu, X., 2017. Quantifying annual changes in built-up area in complex urban-rural landscapes from analyses of PALSAR and Landsat images. ISPRS Journal of Photogrammetry and Remote Sensing, 124, pp. 89-105. doi: 10.1016/j.isprsjprs.2016.12.011.

Shao, Z., Fu, H., Fu, P., Yin, L., 2016. Mapping urban impervious surface by fusing optical and SAR data at the decision level. Remote Sensing, 8 (11), pp. 945. doi:10.3390/rs8110945.

Sinha, S., Jeganathan, C., Sharma, L.K., Nathawat, M.S., 2015b. A review of radar remote sensing for biomass estimation. International Journal of Environmental Science and Technology, 12(5), pp. 1779-1792. doi:10.1007/s13762-0150750-0.

Sinha, S., Jeganathan, C., Sharma, L.K., Nathawat, M.S., Das, A.K., Mohan, S., 2016. Developing synergy regression models with space-borne ALOS PALSAR and Landsat TM sensors for retrieving tropical forest biomass. Journal of Earth System Science, 125(4), pp.725-735. doi:10.1007/s12040-016-0692-z.

Sinha, S., Santra, A., Mitra, S.S., 2018. Automated extraction of built-up areas within forests using remote sensing. In: A. Santra, N.K. Yadav, eds. Proceedings of National Conference on Advancement in Civil Engineering Practice and Research. Excel India Publishers, New Delhi, India. pp. 96-99.

Sinha, S., Sharma, L.K., Nathawat, M.S., 2013. Integrated geospatial techniques for land-use/land-cover and forest mapping of deciduous Munger forests (India). Universal Journal of Environmental Research \& Technology, 3, pp. 190198.

Sinha, S., Sharma, L.K., Nathawat, M.S., 2015a. Improved land-use/land-cover classification of semi-arid deciduous forest landscape using thermal remote sensing. The Egyptian Journal of Remote Sensing and Space Science, 18(2), pp. 217-233. doi:10.1016/j.ejrs.2015.09.005.

Wang, A., Liu, P., Xie, C. 2016. Urban land use classification from high-resolution SAR images based on multi-scale Markov Random Field. In: 24th International Conference on Geoinformatics. Galway, pp. 1-4. 